\title{
STUDENT-FACULTY PARTNERSHIP IN DESIGN: EVALUATING A CO- CREATION PRACTICE AND SHARING OF FINDINGS WITHIN THE SOUTH AFRICAN HIGHER EDUCATION CONTEXT
}

\author{
A. J. M. Botha* \\ Department for Education Innovation \\ e-mail: adriana.botha@up.ac.za / https://orcid.org/0000-0003-3532-3056
}

\author{
A. A. Steyn* \\ Department of Informatics \\ e-mail: riana.steyn@up.ac.za / https://orcid.org/0000-0002-9841-2497
}

*University of Pretoria

Pretoria, South Africa

\section{ABSTRACT}

Creation of content in the higher education context has long been considered as a faculty responsibility. However, a drive towards inclusive curriculum transformation was requested by both students and professional accreditation bodies. Teamwork, as part of partnerships and cocreation, is seen as a critical skill for socio-economic development throughout the world, with the industry expecting competent team players. Faculty has long been incorporating teamwork into modules; however, teaching teamwork and tracking these skills remain challenging. Thus, leaving a gap where students form groups and work in teams without the cognisance to improve their teamwork skills or increase the reliability and validity of evaluating team members' participation and contributions.

In the absence of a comprehensive institutional resource on teamwork fundamentals, this study explores the co-creation of such a resource by post-graduate students at a higher education institution in South Africa. As higher education institutions, we assess students on teamwork skills, but we never specifically teach this to students, this resource is addressing this specific need. This will enable higher education institutions to report on assurance of learning where students can demonstrate the competency to effectively work in teams. A project approach was followed in the design of the teamwork resource based on Mayer's Principles for designing multimedia for elearning. Tuckman's five stage development process informed the content design. The project ran over three weeks with weekly scrum meetings monitored by faculty. The study found that cocreating content with students is possible. However, student partnerships can enable quality improvement of teaching and assessing teamwork skills.

Finally, the researchers will outline how the practical strategies for enacting partnership, as suggested in the literature, were considered in their practice.

Keywords: partnership, co-creation, inclusive curriculum transformation, quality assurance 


\section{INTRODUCTION}

For as long as education exists, content creation has been considered the faculty's responsibility. However, Bovill (2019a; 2019b) argues that this should no longer be the case. Bovill argues that we should engage the students to assist with co-creation of content. Steyn, Jordaan and Millard (2017) identified that students enjoy co-creation of content if educators engage them.

To understand the ontology behind student-faculty partnerships and co-creation of knowledge and quality assurance and promotion, the researchers explored related literature and the potential impact it has on student success. In this regard, the authors of the book titled: Engaging Students as Partners in Learning and Teaching (Cook-Sather, Bovill and Felten 2014) incorporated more than a decade's worth of research. Recommendations from the research guided the practical implementation of a Student-Faculty Partnership (SFP) in design (co-creation) at the University of Pretoria (UP) in 2019 and 2020. This can ensure improvements in quality of teaching and assessing teamwork skills.

\section{LITERATURE REVIEW}

\section{Defining quality assurance}

According to Harvey (2007) quality assurance within the higher education environment refers to the standards within an institution, a learning program or a discipline. For this study, quality assurance (QA) is seen as an influential concept which can be defined in many ways in higher education (Matei and Iwanska 2016). Although quality and QA are often used interchangeably, Matei and Iwanska (2016) argues that instead of trying to find a specific definition for these concepts, one should think of quality as a fit for purpose, consistency and transformation. Therefore, this study adopts the stance that QA refers to the process where a set of meaningful and intentional activities are performed (Pachal 2019) to provide a quality resource for a specific purpose and outcome for UP. This resource was designed by post-graduate students, within the UP's official Learning Management System (LMS). It focused on the introduction and development of team skills and team dynamics. For the UP, an opportunity was created for an internal quality initiative, where the implementation of technology could potentially support and enhance the quality of teamwork across the institution. Matei and Iwanska (2016) and Suskie (2015) argued that such an internal initiative could have a much higher impact on student learning than a "tick the box" approach as demanded by the accreditation agencies and boards. 


\section{Teamwork skills development}

Teamwork as part of partnerships and co-creation is a critical skill for socio-economic development throughout the world, with the industry expecting competent team players (Seat, Parsons and Poppen 2013; Shakir 2009; Binkley et al. 2012; Jackson, Sibson and Riebe 2014). Faculty has long been incorporating teamwork into modules; however, teaching teamwork, assessing team members' contribution and participation remains challenging. More so the tracking of outcome performance and students' competency levels. Thus, leaving a gap where students form groups and work in teams without the cognisance to improve their teamwork skills or increase the reliability and validity of evaluating team members' participation and contributions. Without proper development of these skills, the reporting on quality will remain a question.

In the absence of an extensive institutional resource on teaching teamwork fundamentals, this study explores the design of such a resource by post-graduate students from the Department of Informatics at UP. These students have been through the entire process of teamwork during their undergraduate studies honing practical teamwork skills. This experience and feedback obtained from these students provided an opportunity to review the current curriculum on teamwork skills and identify areas for improvement through the partnership. These areas, teaching, developing and assessing teamwork skills, were identified as the gaps which led to the development and the need for such a resource. Bringing their experience to the table ensured that they have the competencies needed to design this resource for ease of adoption and use by undergraduate students engaged in teamwork.

Because they are familiar with Tuckman's five-stage development process it ensured that the development of the resource was based on their own knowledge and experience (Jones 2019). The resource is designed based on the curriculum for forming and moving through the stages of teamwork, incorporating Tuckman's five stages. These stages are:

- forming: establishing relationships, familiarising with the tasks and creating rules of engagement;

- $\quad$ storming: internal group conflict in establishing group structure;

- norming: ideas and opinions are openly expressed, harmonising team efforts;

- $\quad$ performing: start working in established roles through collaboration and support towards a common goal;

- $\quad$ adjourning: providing an evaluation opportunity for team members and acknowledging contributions made. 
Their journey paved the way for an opportunity to create a partnership between faculty and students to design and co-create a team skills development resource by following a structured and quality-assured process.

\section{Why co-create with students?}

Faculty are often hesitant to engage with students in collaboration or so called "partnerships". However, Cook-Sather et al. (2014) argue that if the engagement and relationships are built on shared trust, respect, reciprocity and responsibility, the issues associated with levels of seniority, expertise, power-play and position should not interfere in the development and enhancement of these partnerships.

Relative to this, Bovill and Woolmer $(2019,407)$ make a distinction between "co-creation of the curriculum" (performed during curriculum design before the commencement of the programme) and "co-creation in the curriculum" (usually conducted during the running of the course). They argue that the decision to choose either concept will significantly be influenced by the position of the student and "how this might influence the kinds of curricular co-creation likely to be enacted." The enacted curriculum could refer to the actual content, resources or even inclusion of technology, that students will engage with in the classroom or in an online environment.

The concept of "co-creation" are interchangeably referred to as students being change agents, or producers of content or products, and in other contexts - even students as partners. For this study, the definition for co-creation of learning and teaching as suggested by Bovill (2019a, 6) are adopted. Bovill understood co-creation of learning and teaching as implying a more deeper level of student agency than is often implied by student engagement. She argues that co-creation of teaching and learning takes place when faculty and students work towards a process of creating products, resources or components. These are related to the whole curriculum including methods, practices, and teaching and learning processes. Sanders and Stapper $(2008,6)$ state that co-creation is "any act of collective creativity, i.e. creativity that is shared by two or more people". They further consider co-creation as being broader than just codesign. Co-creation is in this sense "the creativity of designers and people not trained in design, working together in the design and development processes". The students involved in this process were never trained in design; they were, however, at the beginning of the project introduced to Mayer's design principles of multimedia learning (Mayer 2009). The Mayer's principles can be grouped into three focus areas with associated principles.

- Reducing extraneous processing (coherence, signaling, redundancy, contiguity). 
- $\quad$ Managing essential processing (segmenting, pre-training, modality).

- Fostering generative processing (personalisation, voice embodiment).

According to Cook-Sather, Bovill and Felten $(2014,10)$ there are three reasons faculty should consider and proactively engage and co-create with students: (1) "Students have insight into teaching and learning that can make our and their practice more engaging, effective and rigorous; (2) Faculty can draw on student insights not only through collecting student responses but also through collaborating with students to study and design teaching and learning together; and (3) partnerships between students and faculty change the understanding and capacities of both sets of partners - making us all better teachers and learners."

\section{Student-Faculty-Partnership (SFP)}

For Cook-Sather et al. (2014), there are three principles that form the foundation of an SFP: (1) Respect that is seen as an attitude that everyone brings with them to the SFP which include being open to different perspectives and engage in honest and open communication; (2) Reciprocity which refers to the way we interact in the SFP. It is a mutual act of give-andtake which should be done in a balanced and equitable way; (3) Shared responsibility which refers to a "prerequisite and outcome" of SFP (Cook-Sather et al. 2014). In more practical terms, one can refer to shared responsibility as the manifestation of everything that involves respect and reciprocity.

Cook-Sather et al. (2014) further argue that these principles will enhance the quality of the relationships if faculty can create an environment where students are invited to share their insights. This will include making them part of the dialogue to find intentional and meaningful solutions to enhance the quality and Quality assurance (QA) of learning and teaching towards effective student learning and success in teamwork.

Bovill $(2019 \mathrm{~b}, 93)$ presented a tool she described as "Co-creation of Learning and Teaching typology" that can assist faculty in discussing, reflecting and planning a co-creation project. This tool was partially implemented during the data gathering phase of this study incorporating only the relevant questions related to this project.

The tools used for this project included asking the students to complete following statements (Cook-Sather, Bovill and Felten 2014, 198-199):

\footnotetext{
"I am more aware of"

"I am more comfortable with"

"I work and/or interact with students/faculty"
} 
"I am less comfortable and/or I am concerned by"

"If you could make one statement to share with others (students, faculty, administrators, funders) about this work, what would it be?".

Cook-Sather et al. (2014) argue that there are many advantages for students who are part of an SFP. Some of the advantages include confidence in their role and function - cognitively, emotionally and socially; a deeper level of understanding of the curriculum content they are engaged with; the opportunity of gaining experience in the choice and use of technology they are using and implementing. A final advantage is that they can make meaningful progress in their own learning.

The creation and practice of SFP's do not go without potential risks, difficulties or valid concerns. To this end the study acknowledge and considers Cook-Sather et al. (2014) recommendation when faculty wants to introduce an SFP for a specific goal: (1) Student and faculty vulnerability; (2) Underrepresented students and faculty; (3) To use caution and be intentional in your language when you describe the SFP; (4) Address power issues directly; (5) Approach the co-creation of an SFP on a small scale; (6) Be critical in adopting SFP processes and programs; (7) Always keep the institutional context in mind as well as possible more substantial constraints that can emerge during the SFP execution; and (8) manage your expectation that not all students and faculty will embrace your enthusiasm for an SFP.

In conclusion, SFP's as an example can contribute towards an internal QA initiative such as the resource designed by the post-graduate students for this study.

\section{METHODOLOGY}

This project followed a case study approach, where the design of the resource could be developed in a controlled environment.

A group of (8) post-graduate students formed part of the project to assist in the co-creation of a teamwork skills development resource to assist undergraduate students. The main idea behind the project was to design and develop a self-paced online resource to improve teamwork skills. During the initial meeting, the students were informed of findings from previous research (Botha et al. 2018). A five step Teamwork Assessment Cycle (TACTIC) was introduced to ensure the development and improvement of teamwork skills are established between lecturers, support staff and students. The project team were introduced to the TACTIC Framework (Partnership towards improving team participation and contribution skills) (Botha 2019) where a team member assessment online platform was integrated as part of a total teamwork collaboration and assessment cycle (See Figure 1). The proposed framework is the first step to 
introduce a QA process in modules where team member contribution and participation are being assessed by team members using technology.

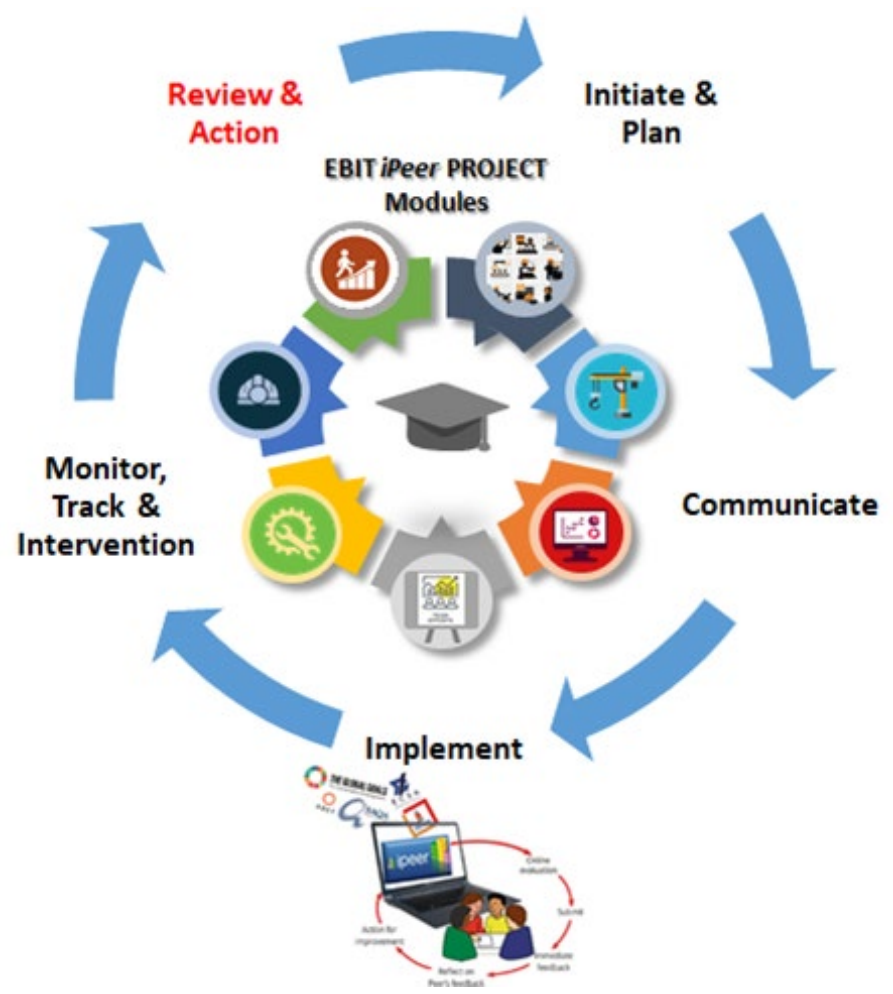

Figure 1: Teamwork Collaboration Assessment Cycle (TACTIC, Botha et al. 2018; 2019)

TACTIC is a five step continuous process, which will now be discussed.

\section{Step 1: Initiate and Plan}

Teamwork activities and assessment opportunities are intentionally planned and designed in alignment with student learning outcomes.

\section{Step 2: Communicate}

Student learning outcomes for teamwork are clearly communicated to students via study guides and lectures. The implementation of TeamUP formed part of this step. Integrating this resource into clickUP as a compulsory self-regulated activity, will address the pressing need of students to learn "teamwork theory".

\section{Step 3: Implement}

Technology to administer assessment for teamwork is implemented. Students are trained in the use of the technology via demonstration in class and online video tutorials. 


\section{Step 4: Monitor}

Monitor and track progress of teamwork assessment. Opportunity for identifying individual students and groups at risk for not being able to complete group outcomes.

\section{Step 5: Review and Action}

Collect and analyse data for teamwork assessment evaluation events. Communicate results to students and lecturers involved in assessment. Review teamwork assessment process, discuss action plans for improvement and thus closing the assessment loop for the next cycle. Implement curriculum and pedagogical changes.

At the end of 2019, UP obtained new software called H5P through Learning Tools Interoperability (LTI). This software allows for the creation of interactive content which can be shared on the official LMS of UP, Blackboard Learn (in-house name - clickUP). H5P also allows for "branching" where the four fundamental topics for effective teamwork are being accessed through a "click", namely: conflict management, communication, peer evaluation, and self-evaluation.

This new software created the opportunity to involve students to co-create interactive content for an online environment with faculty. During the initial meeting, the students were also introduced to Mayer's Principles for designing multimedia for e-learning (Mayer 2009), to ensure that they understand how an online resource should be designed. The students were tasked to create such a resource by following Tuckman's five-stage development process (Jones 2019). The project ran over three weeks with weekly scrum meetings monitored by faculty. During the meetings, progress made was presented to the project team, leading to the analysis and evaluation of the quality and content. All members of the project continuously had access to the content, and could provide feedback as the project was developed. This project was the birth of TeamUP, with three menu topics: UPWay, UPNext, UPThere. The students created these names.

This tool started with a landing page of all menu topics that the students can access via the LMS.

From there one can navigate for the introduction stage, to the screen called UPWay, and is primarily aimed for use by first-year students, or students new to teamwork or to manage team dynamics.

H5P further affords students to engage through interactive videos with multiple-choice questions and quizzes to guide their learning process. H5P also allows marks to be entered into the grade centre of the LMS, and thus one can track each student's progress as they complete the course. Students can receive immediate feedback on their answers provided, and depending 
on the setting, they will be allowed to redo the questions. Students can create and navigate their learning pathway at their own pace.

\section{FINDINGS}

The first realisation was that a bottom-up approach would be the path of least resistance for the introduction of TACTIC and TeamUP and the continuation of SFP to improve on the internal quality assurance initiatives of teamwork. On a micro level, there are many open-minded early adopters. However, on a macro level some resistance might be encountered - the possible reasons being: (1) That there are no formal structures, and policy or frameworks in place for the initiatives; (2) No institutional guidelines/support; (3) Quality assurance are perceived as a managerial action; (4) There are limited institutional broad programme assessment cycles of quality assurance where students are actively involved; (5) No ownership on programme/ module level to identify possible strategies for overcoming $1-4$.

After the first prototype of the resource available, the students were asked to provide some feedback based on their experience on the design and the project.

In total, 7 of the 8 students completed the following summative assessment approach statements (Cook-Sather, Bovill and Felten 2014, 198-199) informing future improvements of such a co-creation and SFP approach. Viewing the feedback from the students, it is clear that this was a positive experience.

\section{Statement: "I am more aware of"}

"How effective teamwork can be in the development of knowledge if managed correctly."

"I am more aware of the fact that there are multiple perspectives and ideas or solutions to a problem. It is important to incorporate all those ideas and perspectives when coming up with the solution."

"How technology can be a great tool to teach students different or new concepts."

\section{Statement: "I am more comfortable with"}

"Teamwork and leadership".

"Being in a creative space and using technical tools."

"Work that I know and can handle as well as understand."

\section{Statement: "I work and/or interact with students/faculty"}

"Student and faculty to produce outcomes". 


\section{Statement: "I am less comfortable and/or I am concerned by"}

"How teamwork is still a big difficulty for students because in industry that is expected."

"Late work, group members saying they know what they are doing, but really don't and people not being treated fairly and respected."

\section{Statement: "If you could make one statement to share with others (students, faculty, administrators, funders) about this work, what would it be?"}

\footnotetext{
"Great experience. Got to develop as a student for a student."

"I wish I had a module like this in my first year to help and guide me through easily manageable problems. It would have simplified my life considerably. This module is really going to assist people and benefit them in so many ways."

"Get a good group where members get along and make an effort to go out with them or get to know them more to form better relationships and improve group work".
}

\section{CONCLUSION}

As researchers and co-faculty, we should investigate opportunities and possibilities to enhance the involvement of students as co-creators in curriculum and pedagogy. By engaging with them in a well-planned Student-Faculty Partnership (SFP), we can empower the students through faculty guidance to help define and shape quality in academic programmes. Thus, co-creating towards fulfilling the assurance of learning for teamwork skills and outcomes required by professional bodies. It was clear from the findings, that the project team felt that using the technology made them aware of various modes of delivering specific content to develop teamwork skills. By positioning the resource within the teamwork collaboration assessment cycle (TACTIC) ensures that the resource is not only available within a program or faculty, but across the institution. Abraham Lincoln once said: "The best way to predict the future is to create it". This study proposes that the best way to predict and achieve student success in teamwork is to create opportunities for it - by designing with students for students!

\section{REFERENCES}

Binkley, M., O. Erstad, J. Herman, S. Raizen, M. Ripley, M. Miller-Ricci and M. Rumble. 2012. Defining twenty-first century skills. In Assessment and teaching of 21st century skills, ed. P. Griffin, B. McGaw and E. Care. Springer, Dordrecht.

Botha, A., A. A. Steyn, L. Weilbach and E. Muller. 2018. Using the iPeer LMS feature to evaluate peer participation in teamwork for assessment "as learning": Lessons learned. In Lecture notes in computer science, ed. T. Hao, W. Chen, H. Xie, W. Nadee and R. Lau, Vol 11284. Springer, Cham (SCOPUS).

Botha, A., S. Bezuidenhout, L. du Plessis, E. Muller, A. A. Steyn, L. Weilbach, R. Jansen, J. Maritz and T. Cronje. 2019. Implementing an online tool for teamwork assessment in real time: A faculty 
initiative across disciplines. In The 5th e-learning excellence awards: An anthology of case histories 2019, ed. D. Remenyi. ACPIL.

Bovill, C. 2019a. Student-staff partnerships in learning and teaching: An overview of current practice and discourse. Journal of Geography in Higher Education, DOI: 10.1080/03098265. 2019.1660628.

Bovill, C. 2019b. A co-creation of learning and teaching typology: What kind of co-creation are you planning or doing? International Journal for Students as Partners 3(2). https://doi.org/ 10.15173/ijsap.v3i2.3953.

Bovill, C. and C. Woolmer. 2019. How conceptualisations of curriculum in higher education influence student-staff co-creation in and of the curriculum. Higher Education 78: 407-422. https://doi.org/ 10.1007/s10734-018-0349-8.

Cook-Sather, A., C. Bovill and P. Felten. 2014. Engaging students as partners in learning and teaching. Jossey-Bass, USA.

Harvey, L. 2007. Epistemology of quality. Perspectives in Education 25(3): 1-13

Jackson, D., R. Sibson and L. Riebe. 2014. Undergraduate perceptions of the development of teamworking skills. Education and Training 56(1): 7-20. https://doi.org/10.1108/ET-01-2013-0002.

Jones, A. 2019. The Tuckman's Model implementation, effect, and analysis and the new development of Jones LSI Model on a small group. Journal of Management 6(4): 23-28. DOI: 10.34218/JOM.6.4.2019.005.

Matei, L. and J. Iwanska. 2016. Quality assurance in higher education: A practical handbook. $1^{\text {st }}$ Edition. Budapest, Hungary: Central European University - Yehuda Elkana Center for Higher Education.

Mayer, R. 2009. Multimedia learning. $2^{\text {nd }}$ Edition. New York, NY, US: Cambridge University press.

Pachal, M. 2019. What is the difference between quality assurance and quality control? https://www.quora.com/profile/Mayur-Panchal-118 (Accessed 25 May 2019).

Sanders, E. B. N. and P. J. Stappers. 2008. Co-creation and the new landscapes of design. CoDesign 4(1): $5-18$.

Seat, E., J. R. Parsons and W. A. Poppen. 2013. Enabling engineering performance skills: A program to teach communication, leadership, and teamwork. Journal of Engineering Education 90(1): 7. https://doi.org/10.1002/j.2168-9830.2001.tb00561.x

Shakir, R. 2009. Soft skills at the Malaysian institutes of higher learning. Asia Pacific Education Rev. 10: 309-315. https://doi.org/10.1007/s12564-009-9038-8.

Steyn, A. A., J. Jordaan and S. Millard. 2017. The use of a learning management system to facilitate student-driven content design: An experiment. In Emerging technologies for education, ed. T. C. Huang, Y. M. Huang, M. Spaniol and C. H. Yuen. SETE. Lecture Notes in Computer Science, Springer, Cham.

Suskie, L. 2015. Five dimensions of quality - A common sense guide to accreditation and accountability. $1^{\text {st }}$ Edition. San Francisco: Jossey-Bass. 